\title{
A note on the water budget of temperate glaciers
}

\author{
J. Oerlemans \\ Institute for Marine and Atmospheric Research Utrecht, Utrecht University, P.O. Box 80005, 3508 TA Utrecht, \\ the Netherlands
}

Correspondence to: J. Oerlemans (j.oerlemans@uu.nl)

Received: 20 May 2013 - Published in The Cryosphere Discuss.: 14 June 2013

Revised: 3 September 2013 - Accepted: 10 September 2013 - Published: 27 September 2013

\begin{abstract}
In this note, the total dissipative melting in temperate glaciers is studied. The analysis is based on the notion that the dissipation is determined by the loss of potential energy due to the downward motion of mass (ice, snow, meltwater and rain). A mathematical formulation of the dissipation is developed and applied to a simple glacier geometry. In the next step, meltwater production resulting from enhanced ice motion during a glacier surge is calculated. The amount of melt energy available follows directly from the lowering of the centre of gravity of the glacier.

To illustrate the concept, schematic calculations are presented for a number of glaciers with different geometric characteristics. Typical dissipative melt rates, expressed as water-layer depth averaged over the glacier, range from a few centimetres per year for smaller glaciers to half a metre per year for Franz Josef Glacier, one of the most active glaciers in the world (in terms of mass turnover).

The total generation of meltwater during a surge is typically half a metre. For Variegated Glacier a value of $70 \mathrm{~cm}$ is found, for Kongsvegen $20 \mathrm{~cm}$. These values refer to water layer depth averaged over the entire glacier. The melt rate depends on the duration of the surge. It is generally an order of magnitude greater than water production by 'normal' dissipation. On the other hand, the additional basal melt rate during a surge is comparable in magnitude with the water input from meltwater and precipitation. This suggests that enhanced melting during a surge does not grossly change the total water budget of a glacier. Basal water generated by enhanced sliding is an important ingredient in many theories of glacier surges. It provides a positive feedback mechanism that actually makes the surge happen. The results found here suggest that this can only work if water generated by enhanced sliding accumulates in a part of the glacier base where surface meltwater and rain have no or very limited access.
\end{abstract}

This finding seems compatible with the fact that, on many glaciers, surges are initiated in the lower accumulation zone.

\section{Introduction}

At first sight the thermodynamics of temperate glaciers are less interesting than those of polythermal glaciers, because the temperature field is homogeneous throughout the glacier by definition (at pressure melting point everywhere). However, all temperate glaciers slide, and with the importance of basal water for the sliding mechanism, the thermodynamics may still play a substantial role. Input into a glacier's hydraulic system may come from meltwater generated at the surface, from rain, and from englacial melting due to dissipation. Intriguing questions thus arise: what is the relative importance of these contributions and how does this depend on the geometric characteristics of a glacier? And, in the case of surging glaciers, how does the extra water input generated by the enhanced dissipation during surge motion compare to the water budget for quiescent conditions?

In this note, the total water budget of a glacier is studied based on a consideration of the integrated energy budget. A simple glacier geometry will be adopted to facilitate the mathematical formulation and illustrate some ideas and concepts. It will be argued that the total dissipation in a glacier system can be estimated from the loss of potential energy associated with the ice's motion and the movement of water through the glacier.

Many processes affect the heat content and thermal structure of a glacier. The surface energy budget, determined mainly by turbulent fluxes and longwave and shortwave (solar) radiative contributions, has been studied thoroughly by the deployment of weather stations (e.g. Oerlemans, 2010). 
When the surface energy flux is positive and the glacier surface is at the melting point, melting will occur and the meltwater can either enter the glacier's hydraulic system or refreeze when it penetrates cold firn. Generally speaking, for the present study the relevance of energy exchange at the glacier surface is twofold: (i) due to the refreezing process, most glaciers in the world are temperate or near-temperate; (ii) meltwater is produced in large amounts.

Basal and englacial processes affecting the heat budget of a glacier are harder to study, because observational data are very scarce. There is dissipation by internal deformation, sliding and running water. For a temperate glacier, heating implies melting of ice. It is therefore possible to estimate the meltwater production from the release of potential energy. Mass added at the glacier surface by the accumulation process leaves the glacier again at the glacier snout, and the associated loss of potential energy can be calculated from purely geometric considerations. When the interest is in the total dissipation within the glacier system, this is much easier than integrating the product of stress and stain rate tensors over the entire ice body.

It should be noted that, for some glaciers in extremely dry climatic conditions, sublimation/evaporation at the glacier surface can be significant. However, for most temperate glaciers, the amount of mass involved in sublimation and evaporation is very small compared to the total mass turnover. Therefore, the approach sketched above should be valid for most temperate glaciers.

The idea of estimating dissipative meltwater production from the loss of potential energy can also be applied to surging glaciers. When a glacier surges, the centre of gravity is lowered and there is a loss of potential energy which is not related to the exchange of mass with the environment. When a surge occurs in a fixed time span, the average water production over that time span due to the surge can be calculated and compared to the water production related to the mass throughput mentioned above, or to the input of surface melt water and rain.

\section{Dissipative water production}

The flow of water through a temperate glacier is a complex process (e.g. Fountain and Walder, 1998; Jansson et al., 2003), with many different mechanisms working in a system that is basically driven by the seasonal cycle in the water input at the surface. Possible pathways of water through a glacier system are shown in Fig. 1. The various sources of water, including dissipative melting due to strain and sliding, are indicated schematically.

Admittedly, the approach taken here will not shed light on the details of water transport through the glacier body, but merely provide estimates of the various components of the total water budget.

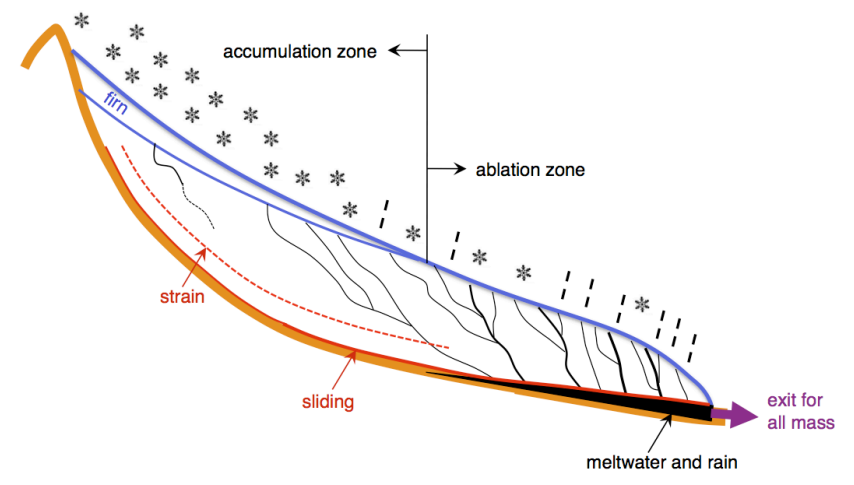

Fig. 1. Components of the mass/water budget of a glacier system. Water from melting and rain enters the glacier by penetration in the firn, or through crevasses and moulins. Water is also produced through dissipative melting by strain (dashed red curve) and sliding (solid red curve). Possible pathways of water through the system are indicated schematically. Transport can be through arborescent englacial channels, and, at the glacier base, linked cavities and subglacial conduits. All mass is assumed to leave the glacier at the glacier snout.

The water budget of a glacier can be formulated as

$$
\frac{\mathrm{d} W}{\mathrm{~d} t}=M+R+D-Q,
$$

where $W$ is the total amount of water in the glacier, $M$ and $R$ are the fluxes of meltwater and rain that enter the glacier and do not refreeze, $D$ is the production of water by dissipation and $Q$ is the runoff at the glacier terminus. The relative magnitude of the various terms depends on the time scale considered. When viewed over a year, the storage term will be small, but it may be large for periods of days or weeks.

The basic idea to be explored in this paper is that the total production of meltwater can be calculated from a consideration of the energy budget of a glacier, and then compared with the other water inputs. The total dissipation can be estimated from the loss of potential energy associated with the motion of ice and water. The first attempt to use such an approach to estimate dissipative heating was made by Oerlemans and Jonker (1985).

The total potential energy $P$ of a glacier is defined as

$P=g \int_{\text {space }} \mu \rho z \mathrm{~d} x \mathrm{~d} y \mathrm{~d} z$.

Here $\mu=1$ when a point in space $\left(x, y, z^{\prime}\right)$ is ice, otherwise $\mu=0$. Furthermore, $\rho$ is ice density and $g$ is the acceleration of gravity. If we assume that the ice density is constant, the total potential energy of a glacier can also be written as:

$P=M g Z$,

where $M$ is the total mass of the glacier and $Z$ is the height of the geometric centre of gravity. When a glacier is in 
steady state, $P$ does not change, because the mass leaving the glacier is replaced by accumulation. However, the dissipation is determined by the loss of potential energy associated with the net downward movement of all the ice particles. As we will see in the next section, for a simplified geometry it is possible to calculate the production of meltwater associated with this. To obtain a feeling for an order of magnitude, one may calculate the amount of ice $q$ that can be melted by dissipation when a block of ice having a mass $m$ travels downwards over a vertical distance $\Delta z$ :

$\frac{q}{m}=\frac{g \Delta z}{L_{\mathrm{m}}}$.

Here $L_{\mathrm{m}}$ is the latent heat of fusion $\left(334 \mathrm{~kJ} \mathrm{~kg}^{-1}\right)$. Taking $g=9.8 \mathrm{~m} \mathrm{~s}^{-2}$ and $\Delta z=1000 \mathrm{~m}$, we find that $q / m=0.029$, so one may state that a few $\%$ of the mass involved in the glacier motion can be melted by dissipative heating.

Most of the meltwater from seasonal snow on a glacier which melts in spring/summer will enter the glacier's hydraulic system. The same applies to rain, which is mainly drained through the glacier rather than over the surface (e.g. Fountain and Walder, 1998). The frictional heating involved when this water finds its way to the glacier front should be taken into account in the total energy budget.

\section{Application to a simple geometry}

We consider the representation of a glacier by a rectangular block of ice of constant width and constant thickness $H$, lying on a bed with a constant slope $s$ (Fig. 2). The bed is given by:

$b(x)=b_{0}-s x$,

where $b_{0}$ is the bed elevation at the glacier head. The precipitation rate (snow plus rain) is assumed to be a linear function of altitude according to

$\dot{p}=\dot{p}_{0}+\gamma h$,

where $\dot{p}$ is the precipitation rate $\left[\mathrm{kg} \mathrm{m}^{-2} \mathrm{~s}^{-1}\right], \dot{p}_{0}$ is the precipitation rate at sea level, $\gamma$ is the altitudinal precipitation gradient $\left[\mathrm{kg} \mathrm{m}^{-3} \mathrm{~s}^{-1}\right]$, and $h$ is the surface elevation. For convenience, $\gamma$ will also be expressed later in $\mathrm{m} \mathrm{a}^{-1} \mathrm{~km}^{-1}$.

For the geometry outlined above, the mean annual precipitation on the glacier is given by

$$
\begin{aligned}
\dot{p}_{\text {ann }} & =\frac{1}{L} \int_{0}^{L} \dot{p}(x) \mathrm{d} x=\frac{1}{L} \int_{0}^{L} \dot{p}_{0}+\gamma\left(b_{0}-s x+H\right) \mathrm{d} x \\
& =\dot{p}_{0}+\gamma\left(b_{0}+H_{\mathrm{m}}\right)-\frac{1}{2} \gamma s L .
\end{aligned}
$$

Various assumptions can be made about the loss of potential energy related to ablation. Ice melts at the surface but

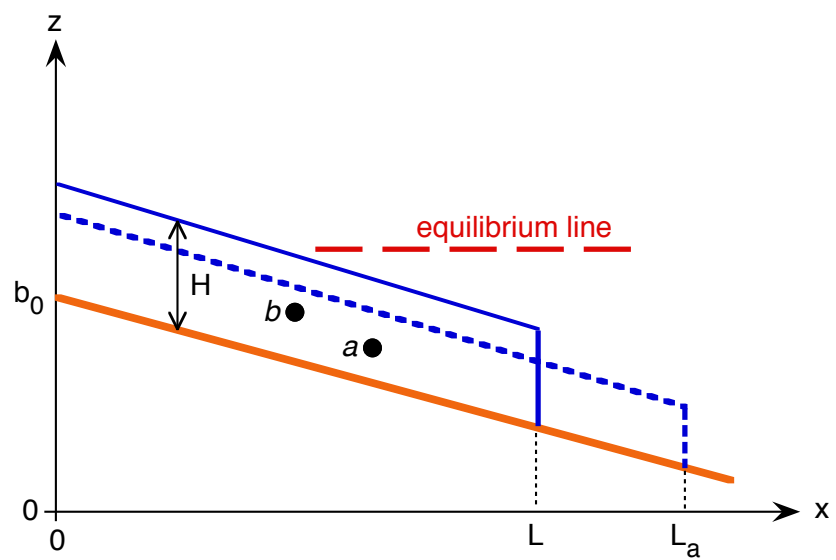

Fig. 2. Simple geometry for the glacier model used in this study (solid line). The dashed profile represents the geometry after a surge. The centres of gravity before $(b)$ and after $(a)$ the surge are indicated by black dots.

then finds its way into the glacier. Most of the kinetic energy associated with the running water in the hydraulic system will be dissipated within the glacier to melt additional ice (for instance at the tunnel walls and at the ice-bed interface). The kinetic energy of the river outflow at the glacier snout is negligible (imagine the speed of a water particle after being accelerated over a $1000 \mathrm{~m}$ vertical distance without any friction). It is thus natural to assume that the loss of potential energy is proportional to $\left(h-b_{L}\right)$, where $b_{L}$ is the height of the bed at the glacier front. Most of the rain falling on glaciers is not drained supraglacially, but quickly finds its way into the internal hydraulic system and contributes to the englacial dissipative melting. In a way this simplifies the formulation of the total dissipation, because it is not necessary to consider snow accumulation and rain separately.

When the model glacier is in steady state, the total dissipation related to mass throughput is thus given by:

$$
\begin{aligned}
\dot{P}_{\mathrm{p}}= & g \int_{0}^{L} \dot{p}(x) h(x)-b_{L} \mathrm{~d} x \\
= & g \int_{0}^{L} \dot{p}_{0}+\gamma\left(b_{0}-s x+H\right)(H-s x+s L) \mathrm{d} x \\
= & g\left[\dot{p}_{0}+\gamma\left(b_{0}+H\right)(H+s L) L-\frac{1}{2} s\left(\dot{p}_{0}+\gamma b_{0}+2 \gamma H\right) L^{2}\right. \\
& \left.+\frac{1}{6} \gamma s^{2} L^{3}\right] .
\end{aligned}
$$

If $\dot{P}_{\mathrm{p}}$ is divided by the latent heat of fusion $L_{\mathrm{m}}$, by the glacier length, and by the density of water, the mean specific meltwater production by dissipation is obtained in $\mathrm{m}$ of water equivalent:

$\dot{m}_{\text {dis }}=\frac{\dot{P}_{\mathrm{p}}}{\rho_{\mathrm{w}} L L_{\mathrm{m}}}$. 


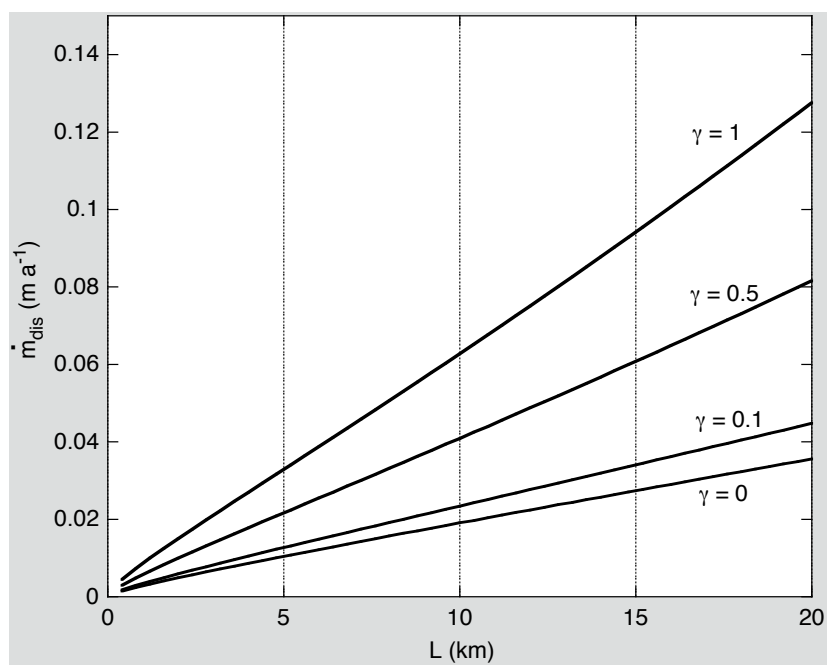

Fig. 3. Mean dissipative melting, averaged over the glacier, as a function of glacier length for different values of the precipitation gradient (labels in $\mathrm{m} \mathrm{a}^{-1} \mathrm{~km}^{-1}$ ). Parameter values: $b_{0}=2000 \mathrm{~m}$, $p_{0}=1000 \mathrm{ma}^{-1}, s=0.1$.

The dissipative meltwater production can now be calculated as a function of, for instance, glacier length. However, mean bed slope, characteristic ice thickness and glacier length are not independent. It is thus meaningful to invoke a relation between these quantities, for example (Oerlemans, 2011, p. 1921):

$H_{\mathrm{m}}=\frac{\alpha_{\mathrm{m}} L^{1 / 2}}{1+v s}$,

where $\alpha_{\mathrm{m}} \approx 3 \mathrm{~m}^{1 / 2}$ and $v \approx 10$ (a dimensionless constant). In Eq. (10), $H_{\mathrm{m}}$ is the mean thickness of the glacier, which is now identified with $H$ as used in the simple geometry of Fig. 2.

In Fig. $3, \dot{m}_{\text {dis }}$ is plotted as a function of $L$ for different values of the precipitation gradient $\gamma$. Other parameter values are: $b_{0}=2000 \mathrm{~m}, p_{0}=1 \mathrm{ma}^{-1}, s=0.1$. This value of $s$ implies a gently sloping glacier; for $L=20 \mathrm{~km}$, the front of the glacier would be at sea level. Note that $L$ is prescribed, and not calculated in relation to a climatic forcing.

First of all, it can be noted that dissipative production of meltwater ranges from a few $\mathrm{cm}$ per year for smaller glaciers to over $10 \mathrm{~cm}$ per year for larger glaciers in a climate with a large precipitation gradient. It should be stressed that the higher values for $\gamma$ used here $(\gamma=0.5$ and $1 \mathrm{~m} \mathrm{a}^{-1} \mathrm{~km}^{-1}$ ) are not uncommon. In the glacier regions in southern Norway, for instance, typical values are between 0.5 and $1.2 \mathrm{~m} \mathrm{a}^{-1} \mathrm{~km}^{-1}$ (Østrem et al., 1988; Oerlemans, 1992; Jansson et al., 2007). Similar values are found in the Alps (e.g. Sevruk, 1997).

In Fig. 4 the result of the theoretical analysis is shown from a different perspective. Now the bed slope is varied for a given glacier length $(5,10$ and $20 \mathrm{~km})$. The altitudinal range

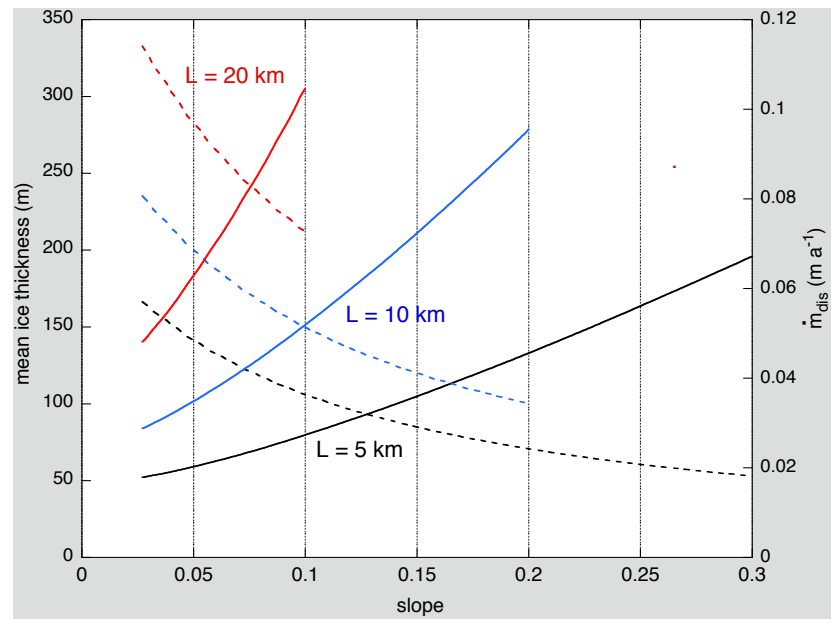

Fig. 4. Ice thickness (dashed, scale at left) and dissipative melt rate (solid lines, scale at right) as a function of bed slope, for three values of the glacier length as indicated in the figure.

has been limited to $2000 \mathrm{~m}$ (recalling that $b_{0}=2000 \mathrm{~m}$ ). Precipitation parameters in this case are: $p_{0}=1 \mathrm{ma}^{-1}$ and $\gamma=0.75 \mathrm{ma}^{-1} \mathrm{~km}^{-1}$.

For a given glacier length, the dissipative melt rate always increases with the slope. For a constant precipitation rate the increase would be linear, but with precipitation depending on height the increase is greater. Steeper glaciers are less thick (dashed lines in Fig. 3), but this only partly compensates for the effect of a wider altitudinal range. Altogether the differences are substantial. For instance, with a bed slope of 0.1 , the dissipative melt rate for a $20 \mathrm{~km}$-long glacier is about five times greater than for a $5 \mathrm{~km}$-long glacier.

In Table 1 , values for $\dot{m}_{\text {dis }}$ for some real glaciers are given, based on rough estimates of the geometric characteristics. The quantity $s$ is taken as the mean glacier slope. Franz Josef Glacier has by far the largest dissipative melting, which is not surprising in view of the enormous mass turnover of this glacier and its relative steepness. In contrast, a small steep glacier like the Dammagletscher in Switzerland has a dissipative melt rate of only a few centimetres per year. From the table one may conclude that a typical dissipative melt rate is $0.1 \mathrm{~m} \mathrm{a}^{-1}$, but that values vary over at least one order of magnitude. It is clear that the dissipative melt rate is much smaller than the water input at the glacier surface.

The equations used so far to estimate dissipative heating are applicable for a simple glacier geometry. However, the procedure can easily be generalized for any glacier geometry. When the surface topography and the spatial distribution of precipitation is known, it is possible to calculate the total loss of potential energy from the mass throughput. 
Table 1. Characteristic values of geometry and precipitation regime for some glaciers, and the calculated mean dissipative melt rate (last column). Data estimated from Swisstopo (Dammagletscher and Rhonegletscher), Anderson et al. (2006) (Franz Josef Glacier), Andreassen and Windsvold (2012) (Nigardsbreen), Björnsson et al. (2003) (Breidamerkurjökull), Van Pelt et al. (2012) (Nordenskiöldbreen).

\begin{tabular}{lcccccc}
\hline Glacier & $\begin{array}{c}L \\
(\mathrm{~km})\end{array}$ & $\begin{array}{c}b_{0} \\
(\mathrm{~m})\end{array}$ & $s$ & $\begin{array}{c}p_{0} \\
\left(\mathrm{~m} \mathrm{a}^{-1}\right)\end{array}$ & $\begin{array}{c}\gamma \\
\left(\mathrm{m} \mathrm{a}^{-1} \mathrm{~km}^{-1}\right)\end{array}$ & $\begin{array}{c}\dot{m}_{\mathrm{dis}} \\
\left(\mathrm{m} \mathrm{a}^{-1}\right)\end{array}$ \\
\hline $\begin{array}{l}\text { Dammagletscher } \\
\begin{array}{l}\text { (Switzerland) } \\
\text { Rhonegletscher } \\
\text { (Switzerland) }\end{array}\end{array}$ & 1.7 & 3400 & 0.5 & 0.5 & 0.75 & $\mathbf{0 . 0 2 5}$ \\
$\begin{array}{l}\text { Franz Josef Glacier } \\
\text { (New Zealand) }\end{array}$ & 11.5 & 2800 & 0.22 & 5.0 & 0.4 & $\mathbf{0 . 4 9}$ \\
$\begin{array}{l}\text { Nigardsbreen } \\
\text { (Norway) }\end{array}$ & 10.5 & 1800 & 0.15 & 2.3 & 1.2 & $\mathbf{0 . 2 3}$ \\
$\begin{array}{l}\text { Breidamerkurjökull } \\
\text { (Iceland) }\end{array}$ & 40 & 850 & 0.025 & 2.0 & 1.5 & $\mathbf{0 . 1 7}$ \\
$\begin{array}{l}\text { Nordenskiöldbreen } \\
\text { (Svalbard) }\end{array}$ & 20 & 900 & 0.045 & 0.25 & 0.25 & $\mathbf{0 . 0 0 7 1}$ \\
\hline
\end{tabular}

\section{Application to surging glaciers}

In this section the theory is expanded to include the effect of a glacier surge on the total dissipation. Observations of surging glaciers have shown that the surge characteristics vary widely. First of all there is the duration of the surge, which varies from one year or less (glaciers in steeper Alpine terrain; e.g. Osipova and Tsvetkov, 1991; Mayer et al., 2011) to up to $10 \mathrm{yr}$ (large and relatively flat glaciers in Svalbard; e.g. Melvold and Hagen, 1998; Sund et al., 2009). The duration of the quiescent phase depends first of all on the climate. Glaciers in wetter climates gain mass in the accumulation area more rapidly, which normally implies a shorter surge cycle.

Basal water plays a central role in the surge mechanism, but observations have not been conclusive about where it comes from. A surge (or mini-surge) can be due to the release of water stored englacially/subglacially or supplied within a short period due to strong ablation or intense rainfall. On many glaciers it has been observed that enhanced water input leads to enhanced ice velocities during a limited period of time (e.g. Iken and Bindschadler, 1986; Anderson et al., 2004; Van de Wal et al., 2008). Large glaciers in Svalbard show sudden accelerations in flow even during winter (Dunse et al., 2011), and these can only be explained by water which suddenly finds its way to a larger area of the glacier bed and facilitates sliding by increasing water pressures.

In some theories of glacier surges, there is a crucial role for water generated by the surging process itself, i.e. caused by frictional heating related to strongly enhanced sliding (Budd, 1975; Kamb et al., 1985; Sharp, 1988; Fowler et al., 2001; Van Pelt and Oerlemans, 2012). It is unclear how large the supply of water from this dissipation process is in relation to the supply of melt water and rain. This is the central question to be investigated now.
During a surge the centre of gravity of a glacier is lowered, irrespective of whether the surge involves a frontal advance or is just a thinning of the upper part and a thickening of the lower part of the glacier. Here we simply assume that during a surge the glacier advances and increases its length by a certain fraction. The post-surge state then has a smaller characteristic ice thickness and a greater length, determined by the conservation of mass (Fig. 2).

A formulation for the change in potential energy during a surge is now derived. First we note that the centre of gravity is at height

$Z=b_{0}-\frac{s L}{2}+\frac{H}{2}$.

Since we assume that mass is conserved, the net balance is zero. This implies (suffix " $b$ " for before surge, suffix "a" for after surge):

$H_{\mathrm{b}} L_{\mathrm{b}}=H_{\mathrm{a}} L_{\mathrm{a}}$.

Writing $L_{\mathrm{a}}=\lambda L_{\mathrm{b}}$, where $\lambda$ is a dimensionless constant, we thus have

$Z_{\mathrm{b}}=b_{0}-\frac{s L_{\mathrm{b}}}{2}+\frac{H_{\mathrm{b}}}{2}$,

$Z_{\mathrm{a}}=b_{0}-\frac{s L_{\mathrm{a}}}{2}+\frac{H_{\mathrm{a}}}{2}=b_{0}-\frac{s \lambda L_{\mathrm{b}}}{2}+\frac{H_{\mathrm{b}}}{2 \lambda}$,

so for the change in potential energy we find:

$\Delta P=g M\left(Z_{\mathrm{a}}-Z_{\mathrm{b}}\right)=-g M\left[\frac{s L_{\mathrm{b}}}{2}(\lambda-1)+\frac{H_{\mathrm{b}}}{2}\left(1-\frac{1}{\lambda}\right)\right]$, 
Table 2. Estimated melt rates for four surging glaciers. In the first four columns some characteristics are given. Note that the mean slope of these glaciers differs widely. In the last column, the dissipative melt rate due to surging is compared to the dissipative melt rate implied by the regular mass turnover. Note that the surging melt rate has the same order of magnitude as the precipitation rate ( $\left.\dot{p}_{\text {ann }}\right)$. Input data from Kamb et al. (1985) (Variegated Glacier), Björnsson et al. (2003) (Tungnaárjökull and Leirufjarjökull), Melvold and Hagen (1998) (Kongsvegen).

\begin{tabular}{|c|c|c|c|c|c|c|c|c|c|}
\hline Glacier & $\begin{array}{c}L \\
(\mathrm{~km})\end{array}$ & $s$ & $\begin{array}{l}T \\
\text { (a) }\end{array}$ & $\lambda$ & $\begin{array}{c}\dot{p}_{\text {ann }} \\
\left(\mathrm{m} \mathrm{a}^{-1}\right)\end{array}$ & $\begin{array}{c}\dot{m}_{\mathrm{dis}} \\
\left(\mathrm{m} \mathrm{a}^{-1}\right)\end{array}$ & $\begin{array}{l}m_{\text {sur }} \\
(\mathrm{m})\end{array}$ & $\begin{array}{c}\dot{m}_{\text {sur }} \\
\left(\mathrm{m} \mathrm{a}^{-1}\right)\end{array}$ & $\dot{m}_{\mathrm{sur}} / \dot{m}_{\mathrm{dis}}$ \\
\hline $\begin{array}{l}\text { Variegated Glac. } \\
\text { (Alaska) }\end{array}$ & 20 & 0.094 & 0.7 & 1.1 & 1.71 & 0.103 & 0.696 & 0.994 & 9.65 \\
\hline $\begin{array}{l}\text { Leirufjarjökull } \\
\text { (Iceland) }\end{array}$ & 5 & 0.130 & 0.5 & 1.2 & 1.08 & 0.022 & 0.431 & 0.862 & 39.2 \\
\hline $\begin{array}{l}\text { Tungnaárjökull } \\
\text { (Iceland) }\end{array}$ & 35 & 0.024 & 0.3 & 1.06 & 1.88 & 0.059 & 0.520 & 1.732 & 29.4 \\
\hline $\begin{array}{l}\text { Kongsvegen } \\
\text { (Norway) }\end{array}$ & 29 & 0.018 & 5 & 1.06 & 0.35 & 0.0061 & 0.191 & 0.038 & 6.23 \\
\hline
\end{tabular}

where $M$ is the total mass of the glacier.

The amount of water generated during the surge, averaged over the glacier, then is (using $M=\rho H_{\mathrm{b}} L_{\mathrm{b}}$ ):

$m_{\text {sur }}=\frac{g \rho H_{\mathrm{b}}}{L L_{\mathrm{m}}}\left[\frac{s L_{\mathrm{b}}}{2}(\lambda-1)+\frac{H_{\mathrm{b}}}{2}\left(1-\frac{1}{\lambda}\right)\right]$.

Later the mean melt rate due to the surge (and averaged over the surge duration) will also be considered. It is defined as

$\dot{m}_{\text {sur }}=m_{\text {sur }} / T$,

where $T$ is the duration of the surge.

With the formulations developed in the previous paragraph, it is now possible to compare the melt rate due to the enhanced ice movement during a surge with the other water inputs. In Table 2, numbers are given for four surging glaciers with very different geometric characteristics. For Variegated Glacier, the "normal" dissipative melt rate is estimated as $0.19 \mathrm{~m} \mathrm{a}^{-1}$ (the term "normal" is used for the dissipation in case of steady state, which is a fictive state for a surging glacier but nevertheless may serve as a useful reference). The total amount of water produced during a surge is calculated to be about $0.70 \mathrm{~m}$. Taking as a typical surge duration 0.7 a (Kamb et al., 1985), this implies a melt rate of $0.99 \mathrm{ma}^{-1}$, i.e. considerably more than the normal dissipative heating.

For the slowest flowing glacier in the sample, Kongsvegen, the normal dissipation is only $0.006 \mathrm{~m} \mathrm{a}^{-1}$, and the water produced during a surge amounts to $0.19 \mathrm{~m}$. Glaciers on Svalbard have a much longer surging phase (typically 5 yr, e.g. Hagen et al., 1998; Sund et al., 2009), implying a melt rate of only $0.038 \mathrm{ma}^{-1}$. However, this is still a far greater rate than the normal dissipative heating. The Icelandic glaciers in the sample, a rather flat one (Tungnaárjökull, which is part of Vatnajökull) and a steeper one (Leirufjarjökull), have surge dissipation rates that are far greater than the normal dissipation rate.

The last column in Table 2 shows values for $\dot{m}_{\text {sur }} / \dot{m}_{\text {dis }}$, typically ranging from 6 to 40. This then leads to a signifi-

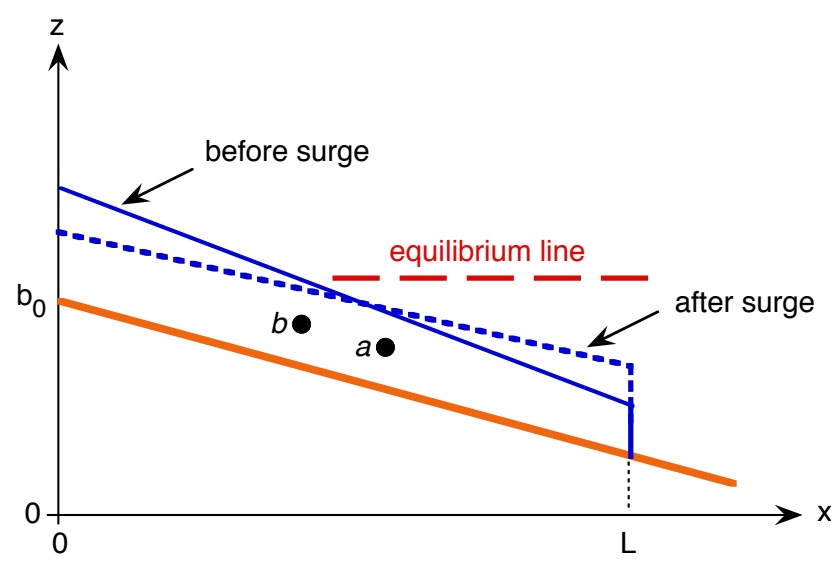

Fig. 5. A sketch showing how a surge without an advance of the glacier front can be represented in the simple geometry used earlier, by adjusting the surface slope (compare with Fig. 2).

cant conclusion: melt water production implied by enhanced glacier movement during a surge is considerably greater than the normal dissipative melt rate. Since the normal dissipative melt rate as defined here is greater than the actual melt rate (because the loss of potential energy during the quiescent phase of a surge cycle will be less than for a fictive steady state situation), the ratios shown in Table 2 are conservative estimates.

In Table 2 the mean precipitation rate on the glaciers $\left(\dot{p}_{\text {ann }}\right)$ is also given. Whether in the form of meltwater or rain, this will also enter the hydraulic system of the glacier (normally supra-glacial discharge is small, e.g. Fountain and Walder, 1998). For Tungnaárjökull and Leirufjarjökull, $\dot{p}_{\text {ann }}$ is about

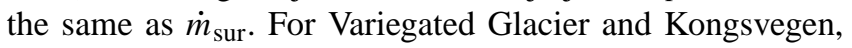
$\dot{p}_{\text {ann }}$ is significantly greater than $\dot{m}_{\text {sur }}$. The second conclusion of these calculations therefore is that the water produced by enhanced glacier movement during a surge does not grossly upset the total water budget of a glacier. In a wet year, the 
same amount of water could be added just because of excessive precipitation.

Concerning the role of dissipative melting in the dynamics of a surging glacier, the findings of this study thus leave two possibilities: (i) water generated by the surging motion itself is less important than previously thought, or (ii) water generated by the surging motion accumulates in a part of the glacier base where surface meltwater and rain have no or very limited access. The second possibility seems to be in line with the fact that many surges are initiated in the lower accumulation zone (e.g. Raymond, 1987; Sund et al., 2009).

At this point it should be noted that the surging mechanism of Variegated Glacier has more to do with a restructuring of the hydraulic system (switch from a tunnel system to a pressurized linked-cavity system) than with the availability of basal water per se (Kamb et al., 1985). Here theories in which the production of water by the surge itself plays a crucial role (e.g. Fowler et al., 2001) are probably less applicable. Nevertheless, it is of interest to calculate the total dissipative melting during a surge and how this compares to other glaciers, as shown in Table 2.

\section{Discussion}

For temperate glaciers, dissipation related to ice motion (deformation and sliding) and running englacial water implies melting of ice. The notion that dissipation in a glacier system can be estimated from the release of potential energy makes it possible to study the effect on the water budget. In this note this has been worked out for a simple glacier geometry, which illustrates the principle of the approach well. When sufficient input data are available, the procedure can also be applied to more complex geometries. However, this will probably not change the major conclusion, namely that the amount of water produced by enhanced ice motion during a surge is larger than that due to the regular mass turnover, but not larger than the amount of water supplied by surface melt and rain.

Surges do not always lead to a significant advance of the glacier front (e.g. Sund et al., 2009). Some surges only lead to thinning in the upper part of a glacier and thickening in the lower part. This also implies a lowering of the centre of gravity, and for a simple schematic representation (Fig. 5) the dissipation can be calculated by analogy with the approach taken for advancing glaciers (not discussed further here). In fact, formulations for the dissipation can be developed for more complex geometries as well, but then it appears to be more useful to use geometries of real glaciers and to evaluate Eq. (2) before and after a surge.

Here only the total water budget has been considered, which is a clear limitation of the theory. A number of quantitative theories of glacier surges have also considered a glacier as a single entity, the dynamics of which can be described by characteristic variables (e.g. the "lumped parameter model" of Fowler et al., 2001; Mayer et al., 2011). Other models with spatial resolution to calculate the ice flow have very simple treatments of basal water. For instance, Flowers et al. (2011) prescribed basal water pressure to match observed sliding velocities. Van Pelt and Oerlemans (2012) calculate the production of basal water explicitly, but do not include a realistic water routing system. The present study suggests that, in future, numerical modelling of glacier surge water inputs from enhanced basal sliding, surface meltwater and rain have to be dealt with in combination with a spatially distributed water routing system.

Transient behaviour has not been considered in this paper. All calculations were carried out for steady states, or for the difference between two steady states (in the case of surges). The theory could be extended to cases where more mass is removed from a glacier than added, or the other way around. However, it is likely that, for steadily retreating or advancing glaciers, the relative importance of the various terms in the water budget will be similar to that for the steady-state cases considered here. Even for strongly retreating glaciers, the flow of mass and surface water through the system remains substantial.

Acknowledgements. I am grateful to Ward van Pelt for his constructive criticism and detailed comments on a draft of this paper. The referees (Anonymous, T. Jóhannesson, D. Brinkerhoff) are thanked for their valuable suggestions for improving the clarity of this paper.

Edited by: M. Sharp

\section{References}

Anderson, B., Lawson, W., Owens, I., and Goodsell, B.: Past and future mass balance of Ka Roimata o Hine Hukatere (Franz Josef Glacier), J. Glaciol., 52, 597-607, 2006.

Anderson, R. S., Anderson, S. P., MacGregor, K. R., Waddington, E. D., O’Neel, S., Riihimaki, C. A., and Loso, M. G. : Strong feedbacks between hydrology and sliding of a small alpine glacier, J. Geophys. Res., 109, F03005, doi:10.1029/2004JF000120, 2004.

Andreassen, L. M. and Winsvold, S. H.: Inventory of Norwegian Glaciers, NVE, Oslo, 236 pp., 2012.

Björnsson H., Pálsson, F., Sigurdsson, O., and Flowers, G. E.: Surges of glaciers in Iceland, Ann. Glaciol., 36, 82-90, 2003.

Budd, W. F.: A first simple model of periodically self-surging glaciers, J. Glaciol., 14, 3-21, 1975.

Dunse, T., Schuler, T. V., Hagen, J. O., and Reijmer, C. H.: Seasonal speed-up of two outlet glaciers of Austfonna, Svalbard, inferred from continuous GPS measurements, The Cryosphere, 6, 453466, doi:10.5194/tc-6-453-2012, 2012.

Flowers, G. E., Roux, N., Pimentel, S., and Schoof, C. G.: Present dynamics and future prognosis of a slowly surging glacier, The Cryosphere, 5, 299-313, doi:10.5194/tc-5-299-2011, 2011.

Fountain, A. G. and Walder, J. S.: Water flow through temperate glaciers, Rev. Geophys., 36, 299-328, 1998.

Fowler, A. C., Murray, T., and Ng, F. S. L.: Thermally controlled glacier surging, J. Glaciol., 42, 527-538, 2001. 
Iken, A. and Bindschadler, R. A.: Combined measurements of subglacial water pressures and surface velocity of the Findelengletscher, Switzerland, Conclusions about drainage systems and sliding mechanism, J. Glaciol., 32, 101-119, 1986.

Jansson, A., Tveito, O. E., Pirinen, P., and Scharling, M.: NORDGRID: a preliminary investigation on the potential for creation of a joint Nordic gridded climate dataset. Norwegian Meteorological Institute, Oslo (DNMI Rapp. 03-2007), 2007.

Jansson, P., Hock, R., and Schneider, T.: The concept of glacier storage: a review, J. Hydrol., 282, 116-129, 2003.

Kamb B., Raymond, C. F., Harrison, W. D., Engelhardt, H. F., Echelmeyer, K. A., Humphrey, N. F., Brugmann, M. M., and Pfeffer, T.: Glacier surge mechanism, 1982-1983 surge of Variegated Glacier, Alaska, Science, 227, 469-479, 1985.

Mayer, C., Fowler, A. C., Lambrecht, A., and Scharrer, K.: A surge of North Gasherbrum Glacier, Karakorum, China, J. Glaciol., 57, 904-916, 2011.

Melvold, K. and Hagen, J. O.: Evolution of a surge-type glacier in its quiescent phase: Kongsvegen, Spitsbergen, 1964-95, J. Glaciol., 44, 394-404, 1998.

Oerlemans J.: The Microclimate of Valley Glaciers. Igitur, Utrecht University, 138 pp., ISBN 987-90-393-5303-5, 2010.

Oerlemans J.: Minimal Glacier Models, 2nd Edn., Igitur, Utrecht University, 103 pp., ISBN 978-90-6701-022-1, 2011.

Oerlemans, J. and Jonker, P. J.: The heat budget of the Antarctic Ice Sheet, Z. Gletscherk. Glazialgeol., 21, 291-299, 1985.

Osipova, G. B. and Tsvetkov, D. G.: Kinematics of the surface of a surging glacier (comparison of the Medvezhiy and Variagated Glacier, IAHS Publ. no.208 (Glaciers-Ocean-Atmosphere Interactions), 345-357, 1991
Østrem, G., Selvig, K. D., and Tandberg, K.: Atlas over breer i SerNorge, Norges "Vassdrags- og Energiverk, Hydrologisk" Avdeling, Meddelelse, 61, 1988

Raymond, C. F.: How do glaciers surge? A review, J. Geophys. Res., 92, 9121-9134, 1987.

Sevruk, B.: Regional dependency of precipitation-altitude relationship in the Swiss Alps, Climate Change, 36, 355-369, 1997.

Sharp, M.: Surging glaciers: behaviour and mechanisms, Prog. Phys. Geog., 12, 349-370, 1988.

Sund, M., Eiken, T., Hagen, J. O., and Kääb, A.: Svalbard surge dynamics derived from geometric changes, Ann. Glaciol., 50, 5060, 2009.

Van de Wal, R. S. W., Boot, W., Van den Broeke, M. R., Smeets, C. J. P. P., Reijmer, C. H., Donker, J. J. A., and Oerlemans, J.: Large and rapid velocity changes in the ablation zone of the Greenland ice sheet, Science, 321, 111-113, 2008.

Van Pelt, W. J. J. and Oerlemans, J.: Numerical simulations of cyclic behaviour in the Parallel Ice Sheet Model (PISM), J. Glaciol., 58, 347-360, doi:10.3189/2012JoG11J217, 2012.

Van Pelt, W. J. J., Oerlemans, J., Reijmer, C. H., Pohjola, V. A., Pettersson, R., and van Angelen, J. H.: Simulating melt, runoff and refreezing on Nordenskiöldbreen, Svalbard, using a coupled snow and energy balance model, The Cryosphere, 6, 641-659, doi:10.5194/tc-6-641-2012, 2012. 